\title{
Mechanochemical Transformation of Planar Polyarene to Curved Fused-Ring System: Solid-Phase Synthesis of Corannulene
}

\author{
Yong Teoh, Gábor Báti, Felipe Garcia* and Mihaiela C. Stuparu*
}

Division of Chemistry and Biological Chemistry, School of Physical and Mathematical Sciences,

Nanyang Technological University, 21 Nanyang Link, 637371 Singapore

*Email: fgarcia@ntu.edu.sg; mstuparu@ntu.edu.sg

ABSTRACT: This work demonstrates that mechanochemical forces can successfully transform a planar polyarene into a curved geometry by creating new $\mathrm{C}-\mathrm{C}$ bonds along the rim of the molecular structure. In doing so, mechanochemistry does not require inert conditions or organic solvents and provide better yields within shorter reaction times. This is illustrated in a 15-minute synthesis of corannulene, a fragment of fullerene $\mathrm{C}_{60}$, in $66 \%$ yield through ball milling of planar tetrabromomethylfluoranthene precursor under ambient conditions. Traditional solution and gas-phase synthetic pathways do not compete with the practicality and efficiency offered by the mechanochemical synthesis, which now opens up a new reaction space for inducing curvature at a molecular level.

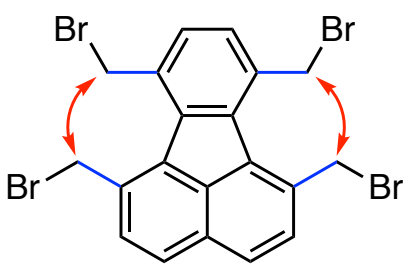

Planar

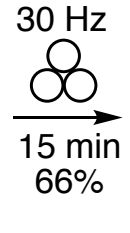

$66 \%$

The synthesis of strained aromatic molecules from strain-free precursors is a challenging task. This requires the natural trigonal planar geometry of the $s p^{2}$-hybridized carbon atoms to become non-planar. The angle strain associated with this pyramidalization needs to be overcome in any viable synthesis. This necessitates application of either high-energy reaction conditions or high-energy precursors. For instance, flash vacuum pyrolysis (FVP), in which molecules are subjected to high temperatures $\left(500-1100{ }^{\circ} \mathrm{C}\right)$ in the gas phase, is the most

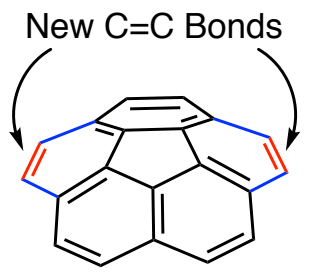

Non-Planar successful synthetic methodology to create nonplanar molecules. ${ }^{1}$ In a landmark publication in 1991, Scott established the utility of FVP as a synthetic method that could bend diethynylfluoranthene, a flat polyarene, into a bowl-shaped aromatic structure, corannulene. ${ }^{2}$ Scott reasoned that the high-energy conditions temporarily populate bent molecular geometries that would be inaccessible under normal circumstances. Only under such folded conformation, the two-carbon side chains could reach across the fluoranthene bay region to 
intramolecularly generate two new 6-membered rings. Ever since, a large family of molecular bowls have been produced through this fascinating method. ${ }^{1}$ A decade later the technique reached a new high in the chemical synthesis of fullerene $\mathrm{C}_{60}{ }^{3}$ This feat of organic synthesis serves as an inspiration to explore new methods that can twist aromatic molecules and create new covalent bonds to lock the curved molecular geometry.

Mechanochemistry, the use of mechanical force to drive chemical reactions, promises sustainable, faster, scalable, and efficient processes. ${ }^{4}$ In this regard, in the past few years, various synthetic techniques such as direct mechanocatalysis ${ }^{5}$ and liquid assisted grinding ${ }^{6-7}$ are developed. New possibilities for heating, ${ }^{8}$ cooling, $^{9}$ and conducting gaseous $^{10}$ mechanochemical reactions are established. Furthermore, analytical techniques for in situ monitoring of the reactions are described. ${ }^{11-12}$ Along with these developments, the application of mechanochemistry for the synthesis of various polyarenes has also been increasing. ${ }^{13}$ So far, however, mechanochemistry is not known to transform planar aromatic molecules into nonplanar structures. We reasoned that mechanochemistry, similar to FVP, creates extraordinary reaction conditions but through impact and shear forces. Such conditions maybe able to bent the molecules such as fluoranthene and allow them to react at the bay regions to form the curved fused-ring system. Unlike FVP, however, mechanochemistry offers no restrictions on the nature of precursors, ${ }^{14}$ a simpler experimental set-up, possible scalability, better yields, shorter times, and operation under ambient conditions. Therefore, it might be a valuable method to access curved structures. To explore this hypothesis, we focused our efforts on tetrabromofluoranthene (1), as a precursor to corannulene synthesis (Scheme 1). This allows for a direct comparison to be made not only with the gas-phase $\mathrm{FVP}^{15}$ but also the conventional solution-phase synthesis. ${ }^{16}$ The results indicate that mechanochemistry is indeed capable of inducing curvature at a molecular level. It is also a practically simple, mild, fast, high-yielding, and a sustainable synthetic approach.

\section{Scheme 1. A comparison of the gas-phase} (right), solid-phase (middle), and liquid-phase (left) synthesis of corannulene.

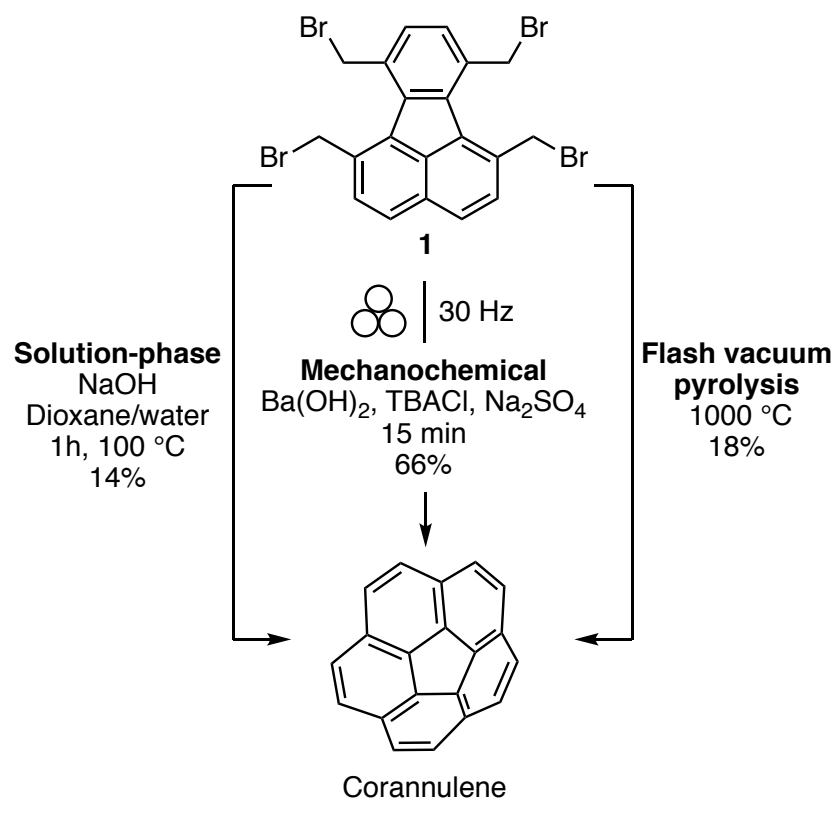


Initially, we focused on the synthesis of precursor 1. The goal was to explore an environmentally friendly approach to access 1 . For this, our investigations began with a key compound, 3,8-dimethylacenaphthenequinone 2, that can be procured from commercial sources. An aldol condensation of $\mathbf{2}$ leads to $\mathbf{3}$, followed by a Diels-Alder reaction to yield 1,6,7,10-tetramethylfluoranthene

4. Tetramethylfluoranthene $\mathbf{4}$ then undergoes benzylic bromination to form precursor 1.

\section{Scheme 2. Synthesis of 3.}

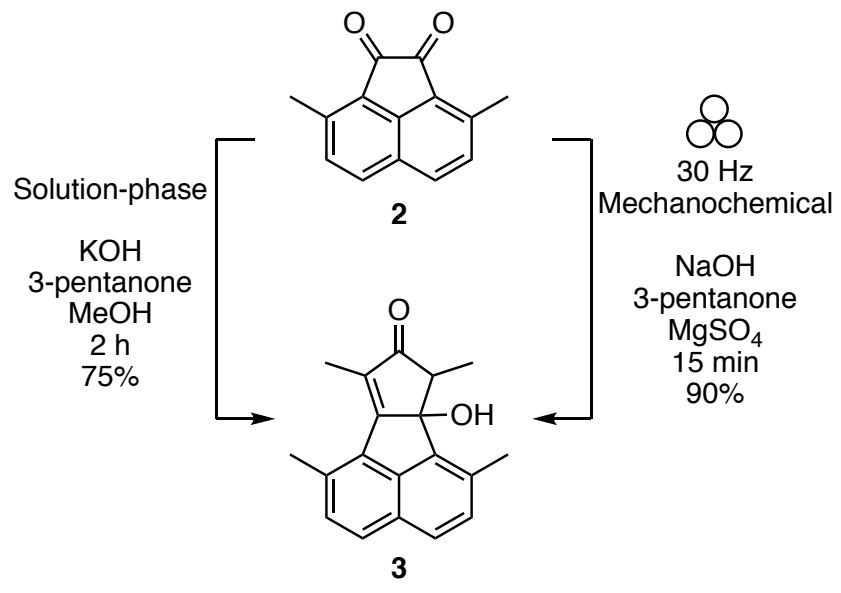

The aldol condensation of 3,8dimethylacenaphthenequinone $\mathbf{2}$ with 3pentanone was carried out under basic conditions (Scheme 2). Solution-based method requires 22 equiv of $\mathrm{KOH}$ dissolved in methanol to attain a sufficiently high $\mathrm{pH}$ for the reaction. The excess of base must then be tediously neutralized using $\mathrm{HCl}$ to precipitate the product. Excessive acidification causes product $\mathbf{2}$ to irreversibly dimerize to 3a (Scheme S1).

Mechanochemistry circumvents these issues as the reaction is complete within 15 minutes of ball milling using just 2.5 equiv of $\mathrm{NaOH}$ as the base, and $\mathrm{MgSO}_{4}$ as the grinding auxiliary. The crude product requires no chromatographic purification. The reaction is easily scalable to $1 \mathrm{~g}$ with no notable difference in isolated yields. Investigations into the reaction conditions identify $\mathrm{MgSO}_{4}$ as an essential grinding auxiliary, likely serving as both a dehydrating agent and a Lewis acid for the aldol condensation (Table S1). The investigation also emulates other mechanochemical condensation reactions by replacing $\mathrm{NaOH}$ with a milder base, such as $\mathrm{K}_{2} \mathrm{CO}_{3}$. The reaction progresses in this case too, albeit at a slower rate and requiring multiple millings. As a control, an un-milled reaction mixture with $\mathrm{NaOH}$ was stirred with a stir bar with no visible product formation observed after 30 minutes. This persists despite heating the reaction mixture to $50{ }^{\circ} \mathrm{C}$. This contrast in reactivity suggests that ball milling is responsible for the mechanochemical activation of the reaction. Overall, ball milling makes the reaction greener and simplifies the workup by removing the laborious neutralization step of excess $\mathrm{NaOH}$, greatly reducing reaction time and generating cleaner products in higher yields.

\section{Scheme 3. Synthesis of 4 .}




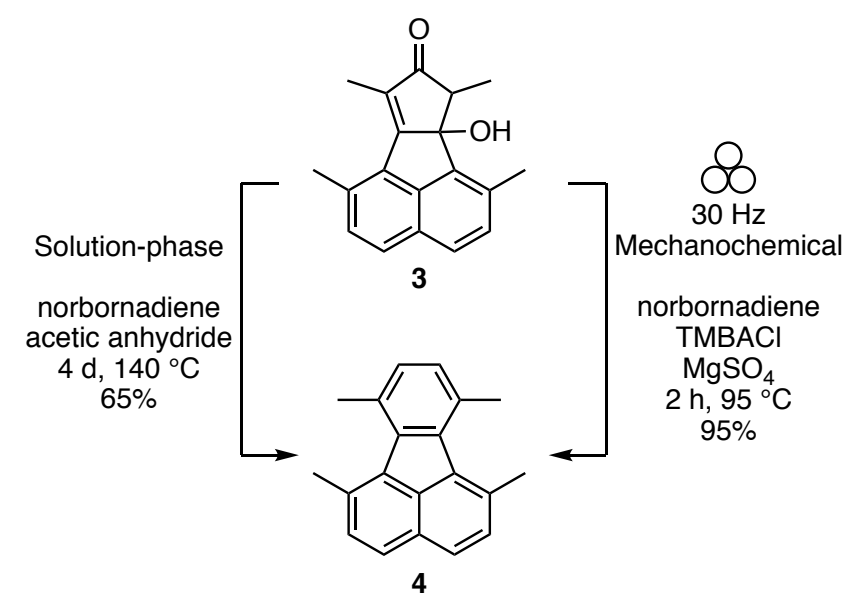

In the next step, compound $\mathbf{3}$ undergoes an inverse electron demand Diels-Alder cheletropic elimination followed by a retro Diels-Alder reaction cascade to generate tetramethylfluoranthene 4 (Scheme 3). Initial milling of compound 3 with $\mathrm{MgSO}_{4}$ and norbornadiene at room temperature generates the dimer 3b only (Scheme S1). This is likely due to the high activation energy required by the Diels-Alder reaction between norbornadiene and 3. This is verified by the successful Diels-Alder reaction of $\mathbf{3}$ with a more reactive dienophile, dimethylacetylene dicarboxylate (Scheme S1, Table S2). Therefore, jars were heated to $95{ }^{\circ} \mathrm{C}$ during the milling process to attain the required activation energy. ${ }^{17}$ This change in milling conditions drives the reaction to completion within 2 hours. In comparison, solution-phase synthesis requires stirring for 4 days at $140{ }^{\circ} \mathrm{C}$ to produce $65 \%$ of 4 . It is important to note that non-tight FTS SmartSnap ${ }^{T M}$ jars were used which allowed the norbornadiene to escape. If a tight FTS or a screw tight jar is used, the yield is halved due to high pressure inhibiting the chelotropic elimination of CO gas, which is part of the reaction cascade. We believe that a custom-made jar equipped with a condenser could greatly reduce the amount of norbornadiene required for the reaction.

\section{Scheme 4. Synthesis of precursor 1.}

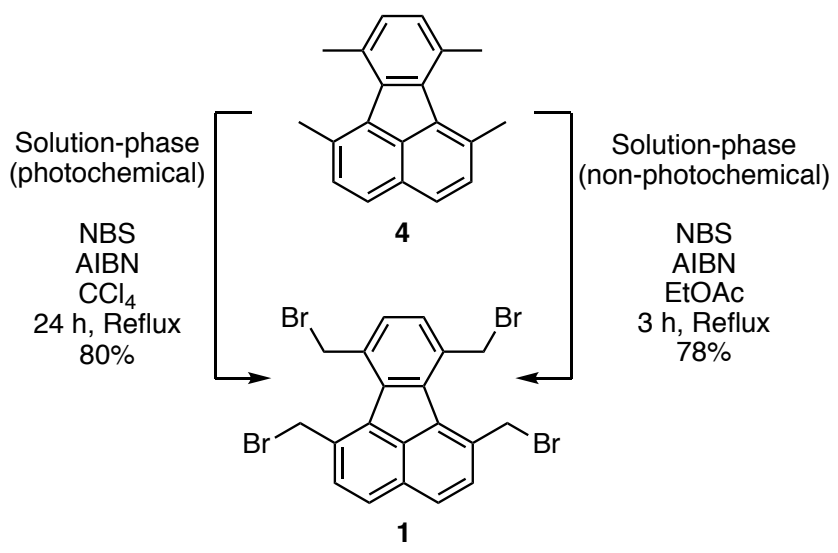

Mechanochemical benzylic bromination of 4 proved to be the most demanding step in this synthesis as ball milling strongly favours aromatic bromination over benzylic bromination, with no literature reported on mechanochemical Wohl-Ziegler bromination. Initial studies using a photomill demonstrated successful benzylic bromination for simple aromatic molecules such as toluene and methylnaphthalene using various milling auxiliaries. However, multi-bromination of more complex molecules such as tetramethylfluoranthene $\mathbf{4}$ generates a mixture of mono and dibrominated compounds. The problem is compounded by low light penetration through solids, restricting the future scalability of such reactions. Therefore, other advances in green chemistry were considered in favour of 
mechanochemistry for the synthesis of $\mathbf{1}$ (Scheme 4).

A user and environmentally friendly alternative is using ethyl acetate as the solvent. ${ }^{18}$ Although the mechanism of the reaction is still unknown, ethyl acetate has been proven to be effective for benzylic bromination even in the absence of light. ${ }^{18}$ Although initial reflux in ethyl acetate only generates a complex mixture of mono and dibrominated products, the addition of azobisisobutyronitrile (AIBN) as a free-radical source resolves this, generating tetrabromomethylfluoranthene within 3 hours (Table S3). The crude product can be subjected to the next reaction. However, to achieve better results, a pure product can be isolated at $78 \%$ yield by washing the crude mixture with small amounts of hot ethyl acetate. In comparison, solution-phase synthesis requires a light source, an excess of NBS, and provides $80 \%$ yield in 24 hours of reaction time in toxic $\mathrm{CCl}_{4}{ }^{15}$

Initial milling of 4 with $\mathrm{NaOH}$ or $\mathrm{NaOt}-\mathrm{Bu}$ produced low yields (2-5\%) of corannulene (Table S4). Addition of tetrabutylammonium chloride (TBACl) increases the yield to $16 \%$. Interestingly, pre-milling of $\mathbf{4}$ before addition of the base improves the yield further to $32 \%$. However, it remains relatively low. Therefore, various liquids were added for liquid-assisted grinding but none significantly influenced the outcome of the reaction. Surprisingly, the addition of hydrated milling auxiliary enhances the yield to $68 \%$. Alternatively, the base can be used in its hydrated form. In both cases, relatively high ( $>65 \%$ ) yields can be obtained. In comparison, FVP at $1000{ }^{\circ} \mathrm{C}$ provides $18 \%$ yield for this reaction. ${ }^{15}$ Similarly, solution-phase synthesis gives an isolated yield of $14 \%$ from precursor $\mathbf{1}^{16}$

Finally, a comparison can be made with an optimized solution-phase synthesis of corannulene $^{19}$ which employs the high-energy octabrominated precursor 5 (Scheme 5 and Scheme S2). ${ }^{20}$ The excessive bromination in $\mathbf{5}$ means that an additional debromination step is required to obtain corannulene. Compared to this optimized synthesis of corannulene, the present synthesis, beginning with dimethylacenaphthenequinone, improves overall yield by $17 \%$, reduces overall reaction time from a few days to a few hours, and reduces the amounts of the reagents required (Scheme S2). Finally, it eliminates the need for the environmentally harmful solvents such as chlorobenzene from corannulene synthesis.

Scheme 5. A comparison of the present synthesis (right) with the optimized kg scale solution-phase synthesis (left) of corannulene. 


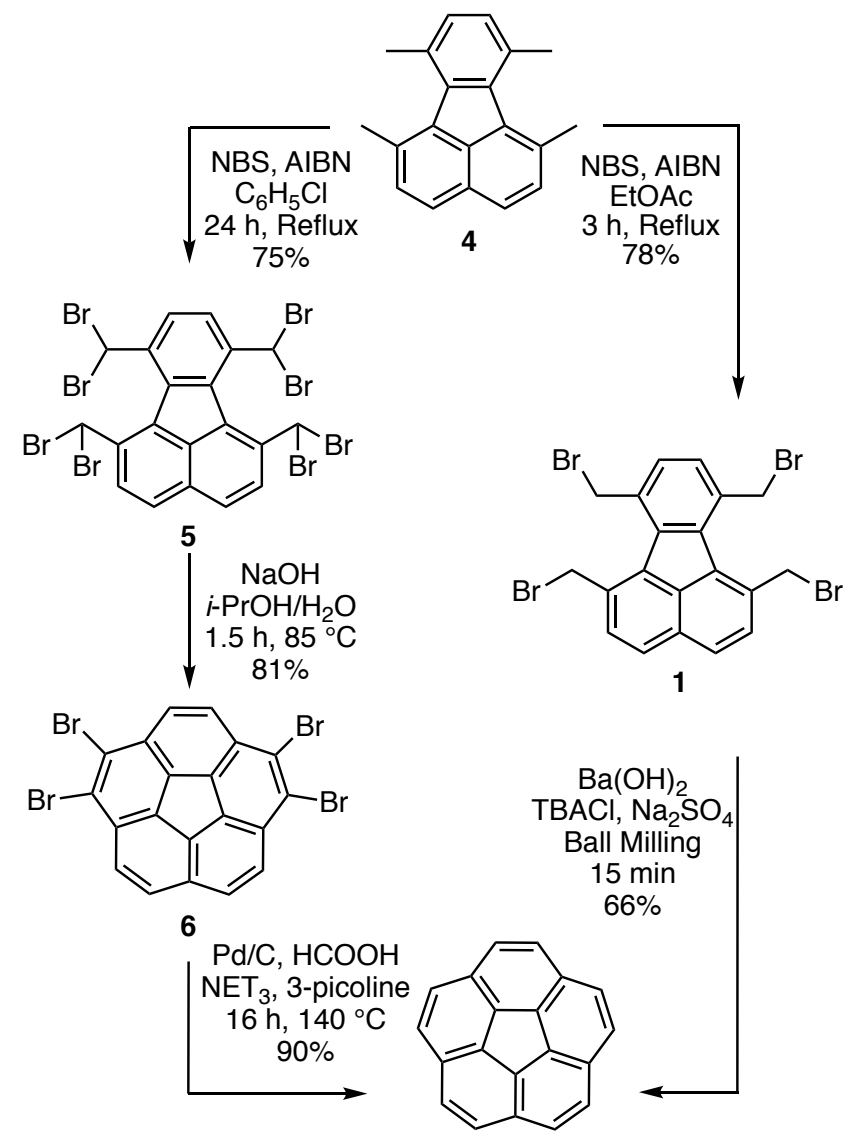

In summary, mechanochemistry offers a promising alternative to conventional gas-phase and solution-based synthetic methods in inducing molecular curvature. With the help of corannulene, it can be demonstrated that the solid-phase synthesis is practically simple. It can be carried out under ambient conditions and requires a shorter reaction time while producing a higher yield. Unlike FVP, it does not require a volatile precursor or high-energy conditions. Unlike solution-phase synthesis, it does not require a high-energy precursor or solvents. Overall, therefore, given the potential of scalability and the challenges in developing highyielding sustainable synthesis of curved fusedring systems, mechanochemistry appears to be a worthy alternative to the traditional solution and gas-phase chemistries.

\section{ASSOCIATED CONTENT}

\section{Supporting Information}

Synthetic details

(PDF)

\section{Notes}

The authors declare no competing financial interest.

\section{ACKNOWLEDGMENT}

Financial support from the Ministry of Education Singapore under the AcRF Tier 1 (MOE2017-T1001-17, M4011792) (2018-T1- 001-176, M4012047); Agency for Science, Technology and Research (A*STAR)-AME IRG A1883c0006 and A1783c0003; and NTU (M4081566, M4080552) is gratefully acknowledged.

\section{REFERENCES}

(1) (a) Scott, L. T., Fragments of fullerenes: Novel syntheses, structures and reactions. Pure Appl. Chem. 2009, 68, 291-300; (b) Tsefrikas, V. M.; Scott, L. T., Geodesic Polyarenes by Flash Vacuum Pyrolysis. Chem. Rev. 2006, 106, 48684884; (c) Scott, L. T., Methods for the chemical synthesis of carbon nanotubes: an approach based on hemispherical polyarene templates. Pure Appl. Chem. 2017, 89, 809-820.

(2) Scott, L. T.; Hashemi, M. M.; Meyer, D. T.; Warren, H. B., Corannulene. A convenient new synthesis. J. Am. Chem. Soc. 1991, 113, 7082 7084.

(3) (a) Boorum, M. M.; Vasilev, Y. V.; Drewello, T.; Scott, L. T., Groundwork for a Rational Synthesis of $\mathrm{C}_{60}$ : Cyclodehydrogenation of a $\mathrm{C}_{60} \mathrm{H}_{30}$ Polyarene. Science 2001, 294, 828; (b) Scott, L. T.; Boorum, M. M.; McMahon, B. J.; Hagen, S.; Mack, J.; Blank, J.; Wegner, H.; de Meijere, A., A Rational Chemical Synthesis of $C_{60}$. Science 2002, 295, 1500; (c) Scott, L. T., Methods 
for the chemical synthesis of fullerenes. Angew. Chem. Int. Ed. 2004, 43, 4994-5007.

(4) For review articles, see: (a) Rodríguez, B.; Bruckmann, A.; Rantanen, T.; Bolm, C., SolventFree Carbon-Carbon Bond Formations in Ball Mills. Adv. Syn. Cat. 2007, 349, 2213-2233; (b) James, S. L.; Adams, C. J.; Bolm, C.; Braga, D.; Collier, P.; Friščić, T.; Grepioni, F.; Harris, K. D.; Hyett, G.; Jones, W.; Krebs, A.; Mack, J.; Maini, L.; Orpen, A. G.; Parkin, I. P.; Shearouse, W. C.; Steed, J. W.; Waddell, D. C., Mechanochemistry: opportunities for new and cleaner synthesis. Chem. Soc. Rev. 2012, 41, 413-47; (c) Ralphs, K.; Hardacre, C.; James, S. L., Application of heterogeneous catalysts prepared by mechanochemical synthesis. Chem. Soc. Rev. 2013, 42, 7701-18; (d) Wang, G. W., Mechanochemical organic synthesis. Chem. Soc. Rev. 2013, 42, 7668-700; (e) Hernández, J. G.; Bolm, C., Altering Product Selectivity by Mechanochemistry. J. Org. Chem. 2017, 82, 4007-4019; (f) Howard, J. L.; Sagatov, Y.; Repusseau, L.; Schotten, C.; Browne, D. L., Controlling reactivity through liquid assisted grinding: the curious case of mechanochemical fluorination. Green Chem. 2017, 19, 2798-2802; (g) Gečiauskaitè, A. A.; García, F., Main group mechanochemistry. Beilstein J. Org. Chem. 2017, 13, 2068-2077; (h) Do, J. L.; Friščić, T., Mechanochemistry: A Force of Synthesis. ACS Cent. Sci. 2017, 3, 13-19; (i) Bolm, C.; Hernández, J. G., From Synthesis of Amino Acids and Peptides to Enzymatic Catalysis: A Bottom-Up Approach in Mechanochemistry. ChemSusChem 2018, 11, 1410-1420; (j) Howard, J. L.; Cao, Q.; Browne, D. L., Mechanochemistry as an emerging tool for molecular synthesis: what can it offer? Chem. Sci. 2018, 9, 3080-3094; (k) Andersen, J.; Mack, J., Mechanochemistry and organic synthesis: from mystical to practical. Green Chem. 2018, 20, 1435-1443; (I) Howard, J. L.; Brand, M. C.; Browne, D. L., Switching Chemoselectivity: Using Mechanochemistry to Alter Reaction Kinetics. Angew. Chem. Int. Ed. 2018, 57, 16104-16108; (m) Tan, D.; Garcia, F., Main group mechanochemistry: from curiosity to established protocols. Chem. Soc. Rev. 2019, 48, 2274-2292; (n) Colacino, E.; Porcheddu, A.;
Charnay, C.; Delogu, F., From enabling technologies to medicinal mechanochemistry. React. Chem. Eng. 2019, 4, 1179-1188; (o) Friščić, T.; Mottillo, C.; Titi, H. M., Mechanochemistry for Synthesis. Angew. Chem. Int. Ed. 2020, 59, 1018-1029; (p) Pickhardt, W.; Grätz, S.; Borchardt, L., Direct Mechanocatalysis: Using Milling Balls as Catalysts. Chem. Eur. J. 2020, 26, 12903-12911.

(5) (a) Fulmer, D. A.; Shearouse, W. C.; Medonza, S. T.; Mack, J., Solvent-free Sonogashira coupling reaction via high speed ball milling. Green Chem. 2009, 11, 1821-1825; (b) Cook, T. L.; Walker, J. A.; Mack, J., Scratching the catalytic surface of mechanochemistry: a multi-component CuAAC reaction using a copper reaction vial. Green Chem. 2013, 15, 617-619; (c) Vogt, C. G.; Grätz, S.; Lukin, S.; Halasz, I.; Etter, M.; Evans, J. D.; Borchardt, L., Direct Mechanocatalysis: Palladium as Milling Media and Catalyst in the Mechanochemical Suzuki Polymerization. Angew. Chem. Int. Ed. 2019, 58, 18942-18947; (d) Grätz, S.; Oltermann, M.; Vogt, C. G.; Borchardt, L., Mechanochemical Cyclodehydrogenation with Elemental Copper: An Alternative Pathway toward Nanographenes. ACS Sustain. Chem. Eng. 2020, 8, 7569-7573.

(6) For review of this area, see: Bowmaker, G. A., Solvent-assisted mechanochemistry. Chem. Commun. 2013, 49, 334-48.

(7) (a) Friščić, T.; Trask, A. V.; Jones, W.; Motherwell, W. D. S. Screening for Inclusion Compounds and Systematic Construction of Three-Component Solids by Liquid-Assisted Grinding. Angew. Chem. Int. Ed. 2006, 45, 75467550; (b) Cao, Q.; Howard, J. L.; Crawford, D. E.; James, S. L.; Browne, D. L., Translating solid state organic synthesis from a mixer mill to a continuous twin screw extruder. Green Chem. 2018, 20, 4443-4447; (c) Chen, L.; Regan, M.; Mack, J., The Choice Is Yours: Using LiquidAssisted Grinding To Choose between Products in the Palladium-Catalyzed Dimerization of Terminal Alkynes. ACS Catalysis 2016, 6, 868872; (d) Belenguer, A. M.; Friščić, T.; Day, G. M.; Sanders, J. K. M., Solid-state dynamic combinatorial chemistry: reversibility and 
thermodynamic product selection in covalent mechanosynthesis. Chem. Sci. 2011, 2, 696-700.

(8) (a) Crawford, D.; Casaban, J.; Haydon, R.; Giri, N.; McNally, T.; James, S. L., Synthesis by extrusion: continuous, large-scale preparation of MOFs using little or no solvent. Chem. Sci. 2015, 6, 1645-1649; (b) Crawford, D. E.; Wright, L. A.; James, S. L.; Abbott, A. P., Efficient continuous synthesis of high purity deep eutectic solvents by twin screw extrusion. Chem. Commun. 2016, 52, 4215-4218; (c) Cindro, N.; Tireli, M.; Karadeniz, B.; Mrla, T.; Užarević, K., Investigations of Thermally Controlled Mechanochemical Milling Reactions. ACS Sustain. Chem. Eng. 2019, 7, 16301-16309.

(9) (a) Andersen, J.; Mack, J., Insights into Mechanochemical Reactions at Targetable and Stable, Sub-ambient Temperatures. Angew. Chem. Int. Ed. 2018, 57, 13062-13065; (b) Andersen, J.; Brunemann, J.; Mack, J., Exploring stable, sub-ambient temperatures in mechanochemistry via a diverse set of enantioselective reactions. React. Chem. Eng. 2019, 4, 1229-1236.

(10) Bolm, C.; Hernández, J. G., Mechanochemistry of Gaseous Reactants. Angew. Chem. Int. Ed. 2019, 58, 3285-3299.

(11) (a) Friščić, T.; Halasz, I.; Beldon, P. J.; Belenguer, A. M.; Adams, F.; Kimber, S. A. J.; Honkimäki, V.; Dinnebier, R. E., Real-time and in situ monitoring of mechanochemical milling reactions. Nat. Chem. 2013, 5, 66-73; (b) Halasz, I.; Puškarić, A.; Kimber, S. A. J.; Beldon, P. J.; Belenguer, A. M.; Adams, F.; Honkimäki, V.; Dinnebier, R. E.; Patel, B.; Jones, W.; Štrukil, V.; Friščić, T., Real-Time In Situ Powder X-ray Diffraction Monitoring of Mechanochemical Synthesis of Pharmaceutical Cocrystals. Angew. Chem. Int. Ed. 2013, 52, 11538-11541; (c) Užarević, K.; Halasz, I.; Friščić, T., Real-Time and In Situ Monitoring of Mechanochemical Reactions: A New Playground for All Chemists. J. Phys. Chem. Lett. 2015, 6, 4129-4140.

12. (a) Batzdorf, L.; Fischer, F.; Wilke, M.; Wenzel, K.-J.; Emmerling, F., Direct In Situ Investigation of Milling Reactions Using Combined X-ray Diffraction and Raman Spectroscopy. Angew. Chem. Int. Ed. 2015, 54,
1799-1802; (b) Kulla, H.; Wilke, M.; Fischer, F.; Röllig, M.; Maierhofer, C.; Emmerling, F., Warming up for mechanosynthesis temperature development in ball mills during synthesis. Chem. Commun. 2017, 53, 1664-1667; (c) Kulla, H.; Haferkamp, S.; Akhmetova, I.; Röllig, M.; Maierhofer, C.; Rademann, K.; Emmerling, F., In Situ Investigations of Mechanochemical OnePot Syntheses. Angew. Chem. Int. Ed. 2018, 57, 5930-5933.

13. (a) Ravnsbæk, J. B.; Swager, T. M., Mechanochemical Synthesis of Poly(phenylene vinylenes). ACS Macro Letters 2014, 3, 305-309; (b) Zhao, Y.; Rocha, S. V.; Swager, T. M., Mechanochemical Synthesis of Extended Iptycenes. J. Am. Chem. Soc. 2016, 138, 1383413837; (c) Grätz, S.; Beyer, D.; Tkachova, V.; Hellmann, S.; Berger, R.; Feng, X.; Borchardt, L., Chem. Commun. 2018, 54, 5307-5310; (d) Wang, C.; Hill, M.; Theard, B.; Mack, J., A solvent-free mechanochemical synthesis of polyaromatic hydrocarbon derivatives. RSC Advances 2019, 9, 27888-27891; (e) Ardila-Fierro, K. J.; Bolm, C.; Hernández, J. G., Mechanosynthesis of OddNumbered Tetraaryl[n]cumulenes. Angew. Chem. Int. Ed. 2019, 58, 12945-12949; (f) Báti, G.; Csókás, D.; Yong, T.; Tam, S. M.; Shi, R. R. S.; Webster, R. D.; Pápai, I.; García, F.; Stuparu, M. C., Mechanochemical Synthesis of CorannuleneBased Curved Nanographenes. Angew. Chem. Int. Ed. 2020, 59, 21620-21626.

14. Flash vacuum pyrolysis requires the precursor to be able to sublime and withstand the sublimation conditions.

15. Borchardt, A.; Fuchicello, A.; Kilway, K. V.; Baldridge, K. K.; Siegel, J. S., Synthesis and dynamics of the corannulene nucleus. J. Am. Chem. Soc. 1992, 114, 1921-1923.

16. Sygula, A.; Xu, G.; Marcinow, Z.; Rabideau, P. W., 'Buckybowls'-introducing curvature by solution phase synthesis. Tetrahedron 2001, 57, 3637-3644. Reproducing reaction as described here, we have isolated $14 \%$ of corannulene from a complex crude mixture of products.

17. Andersen, J. M.; Mack, J., Decoupling the Arrhenius equation via mechanochemistry. Chem. Sci. 2017, 8, 5447-5453. 
18. de Almeida, L. S.; Esteves, P. M.; de Mattos, M. C. S., Tribromoisocyanuric acid as a green reagent for benzylic bromination of alkylarenes. Tet. Lett. 2015, 56, 6843-6845.
19. Butterfield, A. M.; Gilomen, B.; Siegel, J. S., Kilogram-Scale Production of Corannulene. Org. Process Res. Develop. 2012, 16, 664-676.

20. Sygula, A.; Rabideau, P. W., A Practical, Large Scale Synthesis of the Corannulene System. J. Am. Chem. Soc. 2000, 122, 6323-6324. 